\title{
Pengaruh Augmented Reality sebagai Media Pembelajaran terhadap Minat Belajar Siswa Mata Pelajaran IPA SD Kota Bengkulu
}

\author{
Yessi Oktaviani \\ Universitas Bengkulu \\ yessioktaviani16@gmail.com \\ Herman Lusa \\ Universitas Bengkulu \\ hermandatuk1005@gmail.com \\ Feri Noperman \\ Universitas Bengkulu \\ ferinoperman@unib.ac.id
}

\begin{abstract}
This study aims to determine the effect of the utilization of Augmented Reality as a medium of learning on student interest in science subjects of Class IV SD in Bengkulu City. This research uses quantitative approach with experimental research type. The research method used is quasi experimental method with research design of maching only pretestposttest control group design. The population in this study is all students of grade IV of SD Kota Bengkulu using KTSP curriculum. The sample in this research is the students of grade IVB SDN 82 amounting to 23 students is the experimental class and the IVA class of 24 students is the control class. The instrument used in this research is a questionnaire that uses Likert scale given through pretest that is before the learning takes place and posttest after the learning takes place. Data from this study were analyzed using descriptive analysis, and prerequisite test with normality test, homogeneity test, and inferential analysis. From result of research known result of $t$-test with tcount value of 10,52 and ttable value equal to 1,673. So with tcount $(10,52)>$ ttable $(1,673)$ at $5 \%$ significant level, it can be concluded that there is influence of utilization of Augmented Reality as a learning media to student's interest in science class IV SD Bengkulu City.
\end{abstract}

Keywords: Media Augmented Reality, Interest in Learning, Natural Sciences.

\begin{abstract}
Abstrak
Penelitian ini bertujuan untuk mengetahui pengaruh pemanfaatan Augmented Reality sebagai media pembelajaran terhadap minat siswa pada mata pelajaran IPA Kelas IV SD di Kota Bengkulu. Penelitian ini menggunakan pendekatan kuantitatif dengan jenis penelitian eksperimental. Metode penelitian yang digunakan adalah metode kuasi eksperimen dengan desain penelitian maching only pretest-posttest
\end{abstract}


control group design. Populasi dalam penelitian ini adalah semua siswa kelas IV SD Kota Bengkulu menggunakan kurikulum KTSP. Sampel dalam penelitian ini adalah siswa kelas IVB SDN 82 yang berjumlah 23 siswa adalah kelas eksperimen dan kelas IVA 24 siswa adalah kelas kontrol. Instrumen yang digunakan dalam penelitian ini adalah kuesioner yang menggunakan skala likert yang diberikan melalui pretest yaitu sebelum pembelajaran berlangsung dan posttest setelah pembelajaran berlangsung. Data dari penelitian ini dianalisis menggunakan analisis deskriptif, dan uji prasyarat dengan uji normalitas, uji homogenitas, dan analisis inferensial. Dari hasil penelitian diketahui hasil uji-t dengan nilai thitung 10,52 dan nilai ttabel sebesar 1,673. Jadi dengan thitung $(10,52)>$ ttabel $(1,673)$ pada taraf signifikan 5\%, dapat disimpulkan bahwa ada pengaruh pemanfaatan Augmented Reality sebagai media pembelajaran terhadap minat siswa pada kelas IPA sains IV SD Kota Bengkulu.

\section{Kata kunci: Media Augmented Reality, Minat Belajar, Ilmu Pengetahuan Alam.}

\section{Pendahuluan}

Pada saat ini seseorang harus melek terhadap ilmu pengetahuan. Idealnya dalam pembelajaran IPA siswa dilatih dalam kegiatan intelektual yang kompleks dan tidak hanya sekedar mengingat informasi. Untuk menjadikan orang tersebut melek terhadap ilmu pengetahuan, maka harus diberi wawasan serta keterampilan yang dapat digunakan sehingga dapat mencapai suatu tujuan pembelajaran secara efektif. Pembelajaran IPA seharusnya diarahkan kepada pencapaian tujuan dalam arti luas yaitu pengembangan kepribadian siswa atau disebut dengan siswa yang memiliki literat ilmu dan teknologi atau melek terhadap sains dan teknologi (Winarni, 2012: 11).

Salah satu faktor penting yang mempengaruhi kegiatan pembelajaran yaitu minat belajar, jika berminat terhadap suatu pembelajaran maka siswa tersebut akan memusatkan perhatiannya terhadap pembelajaran tersebut. Itu berarti secara tidak langsung minat belajar dapat mempengaruhi hasil belajar siswa. Sebaliknya siswa yang tidak berminat terhadap pembelajaran maka ia akan menganggap pembelajaran itu sulit, salah satunya pada mata pelajaran IPA.

Siswa mengganggap pembelajaran IPA itu sulit, sehingga menjadi tantangan guru terutama guru SD dapat termotivasi untuk menciptakan suatu pembelajaran yang lebih menarik dan menyenangkan. Menciptakan pembelajaran yang menyenangkan dapat dilakukan dengan pembelajaran yang disesuaikan dengan karakteristik anak SD.

Salah satu karakteristik anak SD yaitu senang menggunakan benda-benda berupa gambaran dari benda kongkret sehingga dalam pembelajaran guru menggunakan media-media semi kongkret. Senada dengan teori J. Bruner dalam Muhsetyo (2009 : 1.12) tiga tingkatan yang perlu diperhatikan dalam mengakomodasikan keadaan peserta didik, yaitu enactive (manipulasi objek langsung), iconic (manipulasi objek tidak langsung), dan symbolic (manipulasi simbol). Akan tetapi, dalam penelitian ini hanya menggunakan tahap iconic yaitu memanipulasi objek tidak langsung, dalam artian anak sudah dapat belajar dengan gambar atau kata-kata. Berdasarkan teori tersebut, untuk memenuhi karakteristik anak SD dapat dilakukan pembelajaran dengan menggunakan media-media semi kongkret. Media pembelajaran tersebut dikemas atau dirancang sesuai dengan pembelajaran atau materi yang berkaitan, dengan adanya media pembelajaran maka anak akan tertarik dan termotivasi dalam 
belajar. Salah satu media yang dapat digunakan dalam pembelajaran yaitu menggunakan media Augmented Reality.

Media Augmented Reality membuat pembelajaran menjadi menarik dan memunculkan motivasi anak dalam belajar. Senada dengan hasil penelitian yang dilakukan oleh Mustika (2015:13) Augmented Reality sebagai media pembelajaran dapat dikategorikan interaktif, menarik dan bermanfaat. Media ini apabila digunakan dalam pembelajaran akan menyebabkan anak termotivasi dan tertarik dalam belajar sehingga memunculkan minat belajar siswa. Media ini dapat digunakan pada mata pelajaran IPA kelas IV SD yaitu SK 11. Memahami hubungan antara sumber daya alam dengan lingkungan, teknologi, dan masyarakat. KD 11.1 Menjelaskan hubungan antara sumber daya alam dengan lingkungan. Materi tentang sumber daya alam terkhususnya hewan.

Media Augmented Rality merupakan media yang dapat digunakan guru untuk menjelaskan materi pelajaran tentang sumber daya alam hewan. Hal ini sesuai dengan hasil penelitian yang dilakukan oleh Atmajaya (2017: 227) yang menyatakan aplikasi $A R$ untuk pembelajaran interaktif bagi anak, dapat digunakan untuk pembelajaran pengenalan hewan dan buah-buahan baik di lingkungan lembaga pendidikan atau pendidikan secara mandiri bagi orang tua.

Menurut Mustika (2015: 277) Augmented Reality merupakan konsep perpaduan antara Virtual Reality dengan World Reality. Objek-objek virtual 2 Dimensi (2D) atau 3 Dimensi (3D) seolah-olah terlihat nyata dan menyatu dengan dunia nyata. Teknologi $A R$ sudah diaplikasikan dalam berbagai bidang yang beragam, termasuk dalam bidang pendidikan. $A R$ memberikan interaksi yang lebih nyata dan merupakan kemajuan dari sebuah metode teknologi yang menjanjikan dan dapat memotivasi pengguna untuk terlibat dalam sistem pembelajaran yang lebih efektif. Media $A R$ dapat membantu kegiatan pembelajaran untuk meciptakan efektifitas dan efisisensi pembelajaran. Dalam penelitian ini akan menggunakan media Augmented Reality yaitu Animal 4D. Aplikasi Augmented Reality untuk metode pembelajaran interaktif bagi anak PAUD, yang dapat digunakan untuk pembelajaran pengenalan hewan dan buah-buahan (Atmajaya, 2017:227).

Berdasarkan latar belakang tersebut peneliti akan melakukan penelitian tentang pengaruh pemanfaatan Augmented Reality sebagai media pembelajaran terhadap minat belajar siswa pada mata pelajaran IPA kelas IV SD di Kota Bengkulu.

\section{Metode}

Penelitian ini menggunakan pendekatan kuantitatif dengan jenis penelitian eksperimen. Metode penelitian yang digunakan yaitu metode quasi eksperimen dengan desain penelitian The Maching Only Pretest-Posttest Control Group Design. Dimana dalam desain ini terdapat dua kelas yang berbeda yang terdiri dari kelas kontrol dan kelas eksperimen. Sebelum melakukan pembelajaran sama-sama diberikan pretest minat belajar siswa baik pada kelas kontrol maupun kelas eksperimen. Setelah itu pada kelas kontrol dilakukan pembelajaran menggunakan media gambar hewan sedangkan di kelas eksperimen menggunakan media Augmented Reality dengan materi yang sama yaitu tentang hewan. Selanjutnya setelah pembelajaran sama-sama diberikan posttest minat belajar siswa baik di kelas kontrol maupun di kelas eksperimen.

Dalam penelitian ini teknik pengambilan sampel yang digunakan yaitu teknik Two Stage Cluster Random Sampling (Winarni, 2011: 109). Tahap pertama peneliti memilih dua SD secara acak dari 40 SD yang menggunakan KTSP yang terpilih 
yaitu SDN 82 kelas eksperimen dan SDN 60 kelas kontrol. Tahap kedua, Peneliti memilih 2 rombongan belajar secara acak terpilih kelas IVB SDN 82 berjumlah 23 siswa merupakan kelas eksperimen dan kelas IVA SDN 60 berjumlah 24 siswa merupakan kelas kontrol.

Instrumen yang digunakan yaitu lembar skala minat dengan 40 pernyataan, responnya sebanyak 5 yaitu SS, S, KS, TS, STS. Lembar skala minat ini disusun sendiri oleh peneliti. Lembar skala minat ini kemudian divalidasi ahli oleh ahli psikologi dan diuji coba ke lapangan. Setelah itu lembar skala minat ini dianalisis uji validitas dan uji reliabilitas. Hasil uji reliabilitas sebesar 0,72 berarti instrumen ini valid dan reliabel sehingga dapat digunakan.

Dalam penelitian ini teknik pengumpulan data yang digunakan yaitu tes. Tes yang terdiri dari pretest dan posttest. Lembar tes dalam penelitian ini yaitu lembar skala minat yang berisi pernyataan yang sama antara kelas eksperimen dan kelas kontrol. Pretest diberikan sehari sebelum memulai pembelajaran. Pengisian lembar pretest dilakukan di sekolah selama 20 menit. Pelaksanaan posttest dilakukan ketika kegiatan belajar selesai sebelum guru menutup pembelajaran, pengisisan lembar posstest dilakukan di sekolah selama 20 menit. Sumber datanya yaitu seluruh sampel dimana seluruh sampel akan mengisi lembar skala minat yang diberikan dengan memberi tanda cheklist pada kolom yang telah disediakan. Daftar pernyataan disusun dengan disertai alternatif jawaban yang sudah disediakan.

Data dari penelitian ini dianalisis menggunakan analisis deskriftif dengan perhitungan mean dan varian, uji prasyarat dengan uji normalitas dan uji homogenitas, dan analisis inferensial dengan uji t.

\section{Hasil}

Tabel 1. Minat Belajar Pretest dan Posttest minat belajar siswa Kelas Eksperimen dan Kelas Kontrol

\begin{tabular}{|c|c|c|c|c|}
\hline \multirow[t]{2}{*}{ Deskripsi } & \multicolumn{2}{|c|}{$\begin{array}{c}\text { Pretest Minat Belajar } \\
\text { Siswa }\end{array}$} & \multicolumn{2}{|c|}{$\begin{array}{c}\text { Posttest Minat Belajar } \\
\text { Siswa }\end{array}$} \\
\hline & Eksperimen & Kontrol & Eksperimen & Kontrol \\
\hline Nilai Tertinggi & 84 & 83 & 95 & 85 \\
\hline Nilai Terendah & 56 & 55 & 66 & 57 \\
\hline Jumlah Nilai & 1722 & 1827 & 1702 & 1788 \\
\hline Rata-rata & 73,43 & 73,04 & 84,09 & 75,25 \\
\hline Standar Deviasi & 8,24 & 7,36 & 8,92 & 8,24 \\
\hline Varian & 67,98 & 54,30 & 79,44 & 67,93 \\
\hline$x^{2}$ hitung & 4,84 & 5,38 & 9,26 & 7,11 \\
\hline $\mathbf{F}_{\text {hitung }}$ & \multicolumn{2}{|c|}{1,25} & \multicolumn{2}{|c|}{2,05} \\
\hline$t_{\text {hitung }}$ & \multicolumn{2}{|c|}{0,48} & \multicolumn{2}{|c|}{10,52} \\
\hline
\end{tabular}

Hasil Uji Statistik Minat belajar siswa SD pada awal pembelajaran

Berdasarkan hasil Tabel 4.1, hasil pretest minat belajar siswa SD menunjukkan ada perbedaan tipis nilai rata-rata minat belajar. Rata- rata kelas eksperimen $(73,43)$ lebih besar dibandingkan nilai rata-rata minat belajar pada kelas kontrol $(73,04)$. Untuk menentukan apakah perbedaan itu signifikan atau tidak maka perlu diuji perbedaan. Sebelum dilakukan uji perbedaan dilakukan uji prasyarat dulu untuk menentukan apakah data parametrik atau nonparametrik. Uji prasyaratnya yaitu uji normalitas dan uji homogenitas. 
Hasil uji normalitas disajikan pada Tabel 4.1 dimana nilai $x^{2}$ hitung sebesar 4,84 dan kelas kontrol $x_{\text {hitung }}^{2}$ sebesar 5,38. Nilai $x^{2}$ tabel pada taraf signifikan $5 \%$ sebesar 11,1 . Artinya $x_{\text {hitung }}^{2}<x_{\text {tabel }}^{2}$. Maka kesimpulannya kelas eksperimen dan kelas kontrol berdistribusi normal.

Hasil uji homogenitas disajikan pada Tabel 4.1 menunjukkan bahwa nilai $\mathrm{F}_{\text {hitung }}$ sebesar 1,25 lebih kecil daripada nilai $\mathrm{F}_{\text {tabel }}$ pada taraf signifikan 5\% sebesar 2,05 Artinya status varian kelas eksperimen dan kelas kontrol berasal dari varian yang homogen.

Dari perhitungan didapatkan data normal dan homogen sehingga selanjutnya dilakukan perhitungan dengan uji-t. Berdasarkan Tabel 4.1 di atas dapat dilihat bahwa nilai hasil perhitungan uji-t menunjukkan nilai thitung sebesar 0,48 lebih kecil daripada nilai tabel pada taraf signifikan 5\% sebesar 1,673. Untuk thitung berada di daerah penerimaan $\mathrm{H}_{\mathrm{o}}$. Artinya tidak terdapat perbedaan dari kemampuan awal kelas eksperimen dan kelas kontrol atau kemampuan awal mereka sama, hal ini memenuhi kriteria desain penelitian The Matching Only Pretest-Posttest Control Group Design karena kemampuan awalnya sama.

\section{Hasil Posttest minat belajar siswa SD}

Posttest minat belajar siswa dilakukan setelah memberikan perlakukan pada kelas eksperimen dan kelas kontrol dalam pembelajaran IPA. Hasil posttest minat belajar siswa SD disajikan pada Tabel 4.1. Hasil posttest minat belajar siswa SD menunjukkan ada perbedaan antara kelas eksperimen dan kelas kontrol. Rata- rata kelas eksperimen $(84,09)$ lebih besar dibandingkan rata-rata kelas kontrol $(75,25)$. Untuk menentukan apakah perbedaan itu signifikan atau tidak maka perlu diuji perbedaan secara statistik. Sebelumnya terlebih dahulu dilakukan uji prasyarat untuk menentukan apakah menggunakan statistik parametrik atau nonparamterik. Uji prasyaratnya yaitu uji normalitas dan uji homogenitas.

Hasil uji normalitas disajikan pada tabel 4.1 dimana nilai $x_{\text {hitung }}^{2}$ sebesar 9,26 dan kelas kontrol $x_{\text {hitung }}^{2}$ sebesar 7,11 . Nilai $x_{\text {tabel }}^{2}$ pada taraf signifikan $5 \%$ sebesar 11,1 . Chi kuadrat hitung kelas eksperimen dan chi kuadrat kelas kontrol lebih kelas lebih kecil daripada chi kuadrat. Kesimpulannya adalah data normal.

Hasil uji homogenitas disajikan pada tabel 4.1 menunjukkan bahwa nilai $\mathrm{F}_{\text {hitung }}$ sebesar 1,16 lebih kecil daripada nilai $\mathrm{F}_{\text {tabel }}$ pada taraf signifikan 5\% sebesar 2,05 Artinya status varian kelas eksperimen dan kelas kontrol berasal dari varian yang homogen.

Hasil uji prasayat menunjukkan bahwa data kelas ekperimen dan kelas normal dan homogen, sehingga dilakukan uji statistik paramterik yaitu uji-t. Berdasarkan tabel 4.1 di atas dapat dilihat bahwa nilai hasil perhitungan uji-t menunjukkan nilai thitung sebesar 10,52 lebih besar daripada nilai t tabel pada taraf signifikan 5\% sebesar 1,673, untuk thitung berada di daerah penerimaan $\mathrm{H}_{\mathrm{a}}$. Dapat disimpulkan bahwa terdapat perbedaan siginifikan minat belajar siswa antara kelas eksperimen dan kelas kontrol.

\section{Pembahasan}

Hasil analisis pretest minat belajar siswa SD pada kelas eksperimen $(73,43)$ dan kelas kontrol $(73,04)$ menunjukkan bahwa tidak ada perbedaan siginifikan. Maka dapat simpulkan bahwa minat awal kedua kelompok itu sama sebelum dilakukan 
penelitian. Setelah itu diberikan perlakuan pada kelas eksperimen menggunakan pembelajaran menggunakan media Augmented Reality sedangkan pada kelas kontrol dilakukan pembelajaran menggunakan media gambar hewan. setelah diberikan perlakukan selanjutnya siswa diberi lembar posttest minat belajar siswa SD. Hasil posttest minat belajar siswa SD pada kelas eksperimen $(84,09)$ dan pada kelas kontrol $(8,24)$ menunjukkan terdapat perbedaan signifikan antara kelas eksperimen dan kelas kontrol.

Perbedaan hasil minat belajar siswa diakhir pembelajaran pada penelitian ini kemungkinan karena pemberian perlakuan berbeda. Selain itu, Perlakuan lain yang kemungkinan mempengaruhi minat belajar seperti materi pelajaran dan model pembelajaran dibuat sama. Dapat disimpulkan bahwa pembelajaran menggunakan Augmented Reality sebagai media pembelajaran dapat mempengaruhi minat belajar siswa. Pengaruh tersebut bersifat positif karena minat belajar siswa yang menggunakan $A R$ lebih tinggi dibandingkan minat belajar siswa yang hanya menggunakan media gambar hewan.

Augmented Reality memberikan pengaruh positif terhadap pembelajaran IPA karena saat pembelajaran siswa menjadi tertarik untuk mengamati hewan yang muncul di layar. Itu berarti aplikasi ini memancing siswa untuk bersikap ilmiah seperti munculnya rasa ingin tahu, percaya diri, objektif terhadap fakta dan jujur (Susanto, 2013: 167-168). Secara tidak langsung media ini juga memfasilitasi siswa untuk mengamati sumber daya alam khusunya hewan. Setelah mengamati gambar yang muncul kemudian siswa menuliskan hasilnya di lembar yang sudah disediakan.

Diakhir pembelajaran didapatkan hasil bahwa minat pada kelas eksperimen tinggi, itu berarti media Augmented Reality memberikan pengaruh positif. Pengaruh positif Augmented Reality terhadap minat belajar siswa disebabkan karena media ini menarik dan interaktif (Mustika, dkk,2015., Mustaqim, dkk, 2017., Atmajaya, 2015). Augmented Reality merupakan media interaktif yang melibatkan keaktifan siswa untuk berinteraksi pada saat mengikuti pembelajaran sehingga membantu siswa dalam mencari pengalaman dan pengetahuan.

Minat merupakan dorongan dalam diri seseorang atau faktor yang menimbulkan ketertarikan atau perhatian secara efektif (Susanto, 2013: 58). Augmented Reality dapat membuat siswa tertarik terhadap suatu pembelajaran ini artinya dapat menumbuhkan minat bejar siswa. Selain itu pada saat pembelajaran siswa antusias mengikuti proses belajar. Siswa yang antusias dalam suatu pembelajaran berarti mereka tertarik pada pembelajaran tersebut. Hal ini senada dengan Slameto (2010: 181) siswa yang tertarik terhadap pembelajaran maka ia akan mengikuti proses belajar dengan rasa suka yang berarti dapat menumbuhkan minat belajar siswa

\section{Simpulan}

Berdasarkan hasil penelitian dari analisis data hasil penelitian menunjukkan bahwa nilai thitung $>$ tabel yaitu 10,52 >1,673 sehingga dapat disimpulkan bahwa Ha diterima yaitu terdapat pengaruh positif media Augmented Reality terhadap minat belajar siswa kelas IV SD Kota Bengkulu.

\section{Saran}

Bagi Guru diharapkan menggunakan Augmented Reality sebagai media pembelajaran, karena dengan menggunakan media pembelajaran ini guru dapat menarik perhatian siswa dengan menciptakan suasana yang aktif dan menyenangkan. 
Bagi Peneliti lain disarankan agar menggunakan Augmented Reality sebagai media pembelajaran IPA ke materi yang lain, selain itu sebaiknya terlebih dahulu melihat kriteria seperti anaknya sudah terbiasa menggunakan gadget serta guru harus sudah menguasai aplikasi ini sehingga media ini dapat diterapkan. Selain itu saat melakukan pembelajaran dengan media ini sebaiknya setiap anak memegang satu handphone agar tidak menimbulkan keributan dan tidak ada anak yang menaiki meja karena sangat antusias untuk melihat.

\section{Referensi}

Atmajaya, D. 2017. Implementasi Augmented Reality untuk Pembelajaran Interaktif, ILKOM Jurnal Ilmiah. Volume 9 Nomor 2. halaman 227-232.

Kamelia, L. 2015. Perkembangan Teknologi Augmented Reality sebagai Media Pembelajaran Interaktif pada Mata Kuliah Kimia Dasar. Jurnal ISTEK, Volume IX No. 1. halaman 238.

Maulana, A. \& Kusuma, W. 2014. Aplikasi Augmented Reality sebagai Media Pembelajaran Tata Surya, Prosiding Seminar Ilmiah Nasional Komputer dan Sistem Intelijen (KOMMIT 2014). Vol. 8 Oktober 2014. halaman 53.

Muhsetyo, G, dkk. 2009. Pembelajaran Matematika SD. Jakarta: Universitas Terbuka.

Mustaqim, I \& Kurniawan, N. 2017. Pengembangan Media Pembelajaran Berbasis Augmented Reality, Jurnal Edukasi Elektro. Vol. 1 No. 1. halaman 36-48.

Mustika, dkk., 2015, Implementasi Augmented Reality Sebagai Media Pembelajaran Interaktif. Citec Journal. Vol. 2 No. 4. halaman 227-291.

Slameto. 2010. Belajar dan Faktor-Faktor yang Mempengaruhinya. Jakarta: PT Rineka Cipta.

Susanto, A. 2013. Teori Belajar dan Pembelajaran Di Sekolah Dasar. Jakarta: Kencana.

Wardani, S. \& Sari, M., W. 2016. Pemanfaatan Teknologi Augmented Reality untuk Media Pembelajaran Pengenalan Objek Geometri Berbasis Web. Jurnal Teknologi Technoscientia. Vol. 8 No. 2. halaman 187. 